This is the peer reviewed version of the following article: Schinkel, M. G., Chambers, C. T., Caes, L. and Moon, E. C. (2017), A Comparison of Maternal versus Paternal Nonverbal Behavior During Child Pain. Pain Pract, 17: 41-51, which has been published in final form at https://doi.org/10.1111/papr.12415. This article may be used for non-commercial purposes in accordance With Wiley Terms and Conditions for self-archiving. 


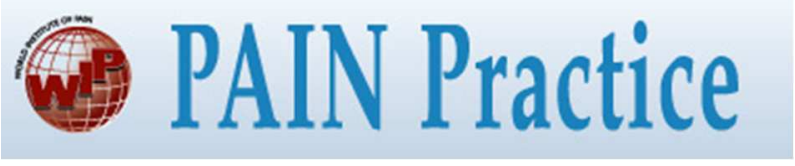

\section{A Comparison of Maternal versus Paternal Nonverbal Behaviour During Child Pain}

\begin{tabular}{|r|l|}
\hline Journal: & Pain Practice \\
\hline Manuscript ID: & Draft \\
\hline Manuscript Type: & Original Manuscript \\
\hline Keywords: & Psychology, Pediatric Pain \\
\hline & \\
\hline
\end{tabular}

SCHOLARONE ${ }^{\text {m }}$

Manuscripts 
Running head: A COMPARISON OF MATERNAL VS. PATERNAL NONVERBAL 1

\begin{abstract}
Parental behaviour plays a significant role in children's pain response. Prior research has found generally no differences between mothers' and fathers' verbal behaviour during child pain. The present study compared mothers' and fathers' nonverbal behaviour during child pain. Nonverbal behaviour of mothers $(n=39)$ and fathers $(n=39)$ of 39 children (20 boys) who participated in the cold pressor task (counterbalanced once with each parent) was coded. A range of nonverbal behaviours were coded, including distraction, physical proximity, physical comfort/reassurance, procedure related attending behaviour, and fidgeting. The most common behaviours parents engaged in were fidgeting, procedure related attending behaviours, and physical proximity. Results indicated that the types of nonverbal behaviour parents engage in did not differ between mothers and fathers. However, children of mothers who engaged in more physical comfort/reassurance reported higher levels of pain intensity, and children of mothers who engaged in more procedure related attending behaviours had lower pain tolerance. Further, both mothers and fathers who engaged in higher levels of verbal non-attending behaviours also engaged in lower levels of nonverbal procedure related attending behaviours.
\end{abstract}

Key words: Child, pain, nonverbal behaviour, mothers, fathers 
A Comparison of Maternal versus Paternal Nonverbal Behaviour During Child Pain

Parental behaviour plays a powerful role in children's response to pain ${ }^{1}$. Parental talk that focuses on child pain (especially reassurance) is associated with higher levels of child pain and distress, whereas the reverse is true for parental talk that is not focused on child pain ${ }^{2,3}$. The majority of research examining parental response to child pain has focused on mothers, despite evidence that fathers have a meaningful and distinct impact in their children's lives (see Lewis and Lamb ${ }^{4}$ for a review), and may be better assessors of child pain than mothers ${ }^{5}$. Exploring both mothers and fathers in pediatric pain is important because parents may influence their children to express pain in sex-typed ways ${ }^{6}$, through differentially reinforcing their daughters' pain displays and minimizing their sons ${ }^{7}$. Preliminary evidence indicates that fathers may be more likely than mothers to encourage these gender stereotypes ${ }^{8}$.

$\mathrm{XXXX}^{9}$ compared mothers' and fathers' verbal behaviour during child cold pressor pain. Parent verbalizations were coded as attending talk (talk focused on the child's pain experience) or non-attending talk (talk not focused on the child's pain experience). Consistent with previous research, they found that parental attending talk was associated with increased child pain levels, while non-attending talk was associated with decreased child pain. However, contrary to their hypothesis, maternal and paternal verbal behaviour largely did not differ. An important limitation of the study was the exclusive focus on parental verbalizations; nonverbal behaviour was not examined.

Although nonverbal behaviour represents an avenue to complement and expand our understanding of pain, few studies have examined parental nonverbal behaviours during child pain. Both pain and emotions can be portrayed, and accurately identified, through nonverbal behaviour $^{10}$, suggesting nonverbal expression can be an important part of communication in pain 
contexts. Further, nonverbal behaviour is thought to be more involuntary than verbal behaviour, and is therefore viewed as more reliable ${ }^{11}$. Some support for the value of examining nonverbal behaviour in pediatric pain comes from McMurtry and colleagues ${ }^{1}$, who found evidence for the importance of parental facial expressions for children in interpreting parental emotions during blood draw procedures. Peterson and colleagues ${ }^{12}$ also found relationships between parental proximity and touch and child pain and distress during cancer procedures. Although these studies highlight the relevance of exploring nonverbal behaviour, both studies focused primarily on mothers. A need for more research exploring the role of sex in nonverbal communication in the pain context has been identified, in order to ascertain whether important sex differences exist ${ }^{13}$. There are currently no known studies that directly compare mothers and fathers nonverbal behaviour during child pain.

Building directly on XXXX and colleagues, ${ }^{9}$ work, the objectives and hypotheses of the present study were to: 1) Describe and compare mothers and fathers nonverbal behaviour during child cold pressor pain. Given the theoretical support for their hypotheses, consistent with XXXX and colleagues ${ }^{9}$ it was hypothesized that fathers would engage in more pain and task oriented nonverbal behaviours with their daughters compared to their sons, whereas mothers would not differentiate. 2) Examine the relationship between mothers' and fathers' nonverbal behaviour and child pain outcomes. It was hypothesized that parental nonverbal behaviours drawing attention to the child's pain experience (e.g., reassuring, comforting) would be related to higher levels of child pain intensity and affect, and lower pain tolerance, while the reverse would be true for behaviours not focused on the pain experience (e.g., distraction, humor). 3) Examine the relationship between mothers' and fathers' verbal and nonverbal behaviour during child pain. It was hypothesized that parental nonverbal behaviours drawing attention to the child's pain 
experience would be positively correlated to verbal attending talk, and negatively correlated to verbal non-attending talk, while the reverse would be true for nonverbal behaviours not focused on the child's pain experience.

\section{Methods}

\section{Participants}

The sample consisted of the 39 healthy children (20 boys and 19 girls) aged 8-12 years $(M=9.66$ years, $S D=1.17)$ and both parents $(39$ mothers and 39 fathers $)$ who participated in the study by XXXX and colleagues ${ }^{9}$. One additional family was excluded from the original sample due to inadequate video quality, specifically the camera angle did not allow for nonverbal behaviour coding. Each child was from a different family, and participated in the task both with their mother and their father. Ninety percent of children were Euro-Canadian. Thirty-eight biological mothers, one stepmother, 37 biological fathers, and two stepfathers participated. Mothers had a mean age of 40.97 years (range $=30-53$ years; $S D=4.92$ ) and $84.6 \%$ of mothers were married. Fathers had a mean age of 42.41 years $($ range $=32-52$ years; $S D=4.76)$ and $87.2 \%$ of fathers were married. Eighty-five percent of mothers and eighty-seven percent of fathers were Euro-Canadian. As reported on the Hollingshed Index ${ }^{14}, 90 \%$ of the families were middle, upper-middle, or upper class.

Exclusion criteria for children for the original study by $\mathrm{XXXX}$ and colleagues ${ }^{9}$ included the child having a developmental delay or chronic medical condition (including chronic pain), current injuries to the hands or arms, and previous participation in a cold pressor task (CPT) study. As reported by XXXX and colleagues ${ }^{9}$, a total of 71 families were screened for eligibility and 23 were excluded. Forty-eight families were enrolled in the study, and eight were excluded. More detail on the reasons for exclusion are available in XXXX and colleagues ${ }^{9}$. 


\section{Apparatus}

The cold pressor device used in the study was a commercially manufactured plastic cooler, which measured $43.5 \mathrm{~cm}$ long, $23.5 \mathrm{~cm}$ wide, and $28.0 \mathrm{~cm}$ deep. The cooler was filled with water and the water temperature was maintained at $10^{\circ} \mathrm{C} \pm 1^{\circ} \mathrm{C}$, as is frequently used and recommended in published guidelines ${ }^{15,16}$. A plastic screen was used to separate the cooler into two sections. The first section contained ice cubes in order to keep the water cool. Children placed their hand through a round opening $(13 \mathrm{~cm}$ diameter) in the lid of the second section to submerge their hand into the water. The CPT is a safe, well accepted, and ethically appropriate task for use with children and induces mild to moderate pain ${ }^{16,17}$.

\section{Measures}

\section{Child pain intensity.}

The Faces Pain Scale-Revised (FPS-R) ${ }^{18}$ was used to measure child pain intensity. This scale is psychometrically sound with children ages 4 through $12^{18}$. The scale consists of six faces that range from no pain to very much pain. Children rated their pain intensity by pointing to the face that showed how much pain they had when their hand was in the water.

\section{Child pain affect.}

The Facial Affective Scale $(F A S)^{19,20}$ was used to measure child pain affect. This scale has demonstrated reliability and validity with children ages 5 years and above ${ }^{19}$. The scale is composed of nine faces that portray a range from the most pleasant feeling to the most unpleasant feeling. Children rated their pain affect by pointing to the face that showed how "unpleasant or yucky" it felt when their hand was in the water.

\section{Child pain tolerance.}


Child pain tolerance was recorded as the length of time each child left their hand immersed in the water during the CPT (up to a maximum of 240 seconds).

\section{Parental verbal behaviour coding.}

In order to permit an examination of the relationships between verbal and nonverbal behavior, the study also utilized the parental verbal behaviour coding described by and presented in XXXX and colleagues $^{9}$. Parental verbal behaviour was coded in the XXXX and colleagues ${ }^{9}$ study as attending talk or non-attending talk, or "other" talk. Only the attending and nonattending categories are reported on in this study. Attending talk referred to parental verbalizations such as symptom-focused talk and commands to the child, sympathy toward the child, procedure-related praise to the child, and procedure time talk and commands to the child. Non-attending talk referred to parental verbalizations such as nonsymptom-focused talk and commands to the child, and humor toward the child. As described by XXXX and colleagues ${ }^{9}$, parent verbal behaviours were transcribed and coded from audiotape. Coding by XXXX and colleagues ${ }^{9}$ demonstrated excellent reliability.

\section{Parental nonverbal behaviour coding.}

The development of the nonverbal behavioural coding system used in the present study was informed by the suggestions outlined by Bakeman and Gottman ${ }^{21}$ as well as the recommendations for development of behavioural coding systems outlined by Chorney, McMurtry, Chambers, and Bakeman ${ }^{22}$. Consistent with the recommendations outlined by Chorney and colleagues ${ }^{22}$, the coding system was developed by reviewing parental behaviours in a small subset of videos and considering nonverbal correlates of typically examined parental verbal behaviour during child pain in the literature. The Child-Adult Medical Procedure Interaction Scale-Revised and Short Form (CAMPIS-R; CAMPIS-SF) are observational rating 
scales of child verbal and nonverbal distress and coping behaviours, and adult verbal and nonverbal coping and distress promoting behaviours during medical procedures, that have demonstrated good reliability and validity ${ }^{23,24}$. The behaviours outlined in these coding systems, and particularly the nonverbal components of the adult coping promoting code described in the CAMPIS-SF ${ }^{24}$ (e.g., distracting the child by pointing to the camera or an object in the room, demonstrating and encouraging the child to use party blowers, and playing with the child), were also used to inform the development of the nonverbal coding system used in the present study. The approach used to develop the coding system lends support for the content and face validity of the present coding system ${ }^{22}$. A final coding manual was developed that consisted of explanations and examples of each behaviour, and is available upon request from the authors.

In this study, parental nonverbal behaviours were coded across 13 categories of behaviour such as distraction, physical comfort and reassurance, procedure related attending behaviours, and fidgeting (see Table 1 for a complete list, with examples, of the nonverbal behaviours included in the coding system). Parental nonverbal behaviours were coded as being either present or not present across 5-second intervals during the cold pressor task. Bakeman and Gottman ${ }^{21}$ describe using intervals between 1-10 seconds as acceptable when doing interval coding, thus an interval of 5 seconds was chosen. Further, rating behaviour as present or absent across 5 second intervals has been used in other observational coding studies in the field of pediatric pain ${ }^{25,26}$. Proportion scores for each category of behaviour were calculated by dividing the number of time intervals in which the behaviour was present by the total number of intervals coded. Proportions were calculated in order to account for the variation in duration in which the child left their hand in the water during the cold pressor task, so as to allow for comparison across parents. Coder training consisted of reviewing the manual, coding practice videos as a group, and coding 
practice videos separately, comparing results, and discussing discrepancies. Coding was completed independently by two research assistants. Reliability coding was completed by a third coder on $20 \%$ of the videos. Percent agreement (using exact agreement as the standard of agreement) across the behaviours ranged from $90.47 \%$ (fidgeting and physical proximity) to 99.63\% (procedure related encouraging/supportive gestures and non-procedure related encouraging/supportive gestures) indicating excellent levels of inter-rater reliability. Although kappa is often used as a measure of inter-rater reliability, kappa can be misleading when variability in the data set is low ${ }^{27}$. Given that many behaviours were coded as occurring at very low frequencies, variability in the data set was indeed low (see Table 2). Therefore, percent agreement was deemed a more representative measure of inter-rater agreement.

\section{Procedure}

Participation in the original study by XXXX and colleagues ${ }^{9}$ involved a single visit to the research centre. The study was approved by the XXXX Research Ethics Board (REB). As described in $\mathrm{XXXX}$ and colleagues ${ }^{9}$, written consent was obtained from the parents and written assent was obtained from the child at the outset of the study. Children in the study completed the cold pressor task once with their mothers present and once with their fathers present in a counterbalanced order. The parent assigned to accompany their child for the first CPT was seated approximately 1.5 feet directly across from their child in a testing room. The child was instructed to use their nondominant hand for the first CPT and their dominant hand for the second CPT. The parent and child were informed that there would be a 2-minute wait period after the researcher left the room, after which a "beep" from a preprogrammed stopwatch would signify that it was time for the child to place their hand up to the wrist fold in the water. The child was asked to keep their hand in the water until they heard a second beep, which would indicate that 4 
minutes had passed. However, the child was instructed that they could remove their hand from the water at any time if it became too uncomfortable. A researcher collected pain intensity and pain affect ratings from the child immediately following the CPT, without the parent present. Children were provided with a 5-mintue break between the first and second CPT where they were provided with fruit juice and a snack. The same procedure was repeated exactly with the parent assigned to join their child for the second CPT. Families were audiotaped and videotaped during the CPT, and the videotapes were used to code parents' nonverbal behaviour during the CPT.

\section{Analyses}

\section{Relationship between parent nonverbal behaviour and child pain outcomes.}

Pearson correlations were conducted (with Bonferroni correction $[\alpha / 13=.004]$ ) separately for mothers and fathers to examine the relationship between maternal and paternal nonverbal behaviour and child pain outcomes (collapsed across boys and girls).

\section{Relationship between parent verbal and nonverbal behaviour.}

A series of Pearson correlations were conducted (with Bonferroni correction $[\alpha / 13=$ .004]) separately for mothers and fathers to examine the relationship between the coded nonverbal behaviours and attending and non-attending verbal behaviours.

\section{Effect of child sex and parent sex on parental nonverbal behaviour.}

A multilevel modeling analysis was used to examine the impact of child sex and parent sex on parental nonverbal behaviour, in order to take into account the non-independence of the data (i.e., mothers and fathers of the same child, while still separate participants, constitute a dyad and are thus not truly independent). The data was hierarchically nested in that parents (mothers and fathers; level 1) were nested within their child (level 2). A series of multilevel 
regression analyses were conducted using the program HLM (Version 7 Student $)^{28}$. Continuous level 2 variables (i.e., child age) were standardized and grand mean centered, and full maximum likelihood estimates were used for all models. The slopes for the first level variables were fixed. The effect size $r$ was calculated, where $r=.10$ is a small effect, $r=.30$ is a medium effect and $r$ $=.50$ is a large effect, for all significant findings ${ }^{29}$.

In the first series of analyses, a baseline model without any predictor variables was conducted for each dependent variable (i.e., each nonverbal behaviour) in order to examine the amount of variance in the dependent variable accounted for within parent dyads (parent variables; level 1) and between parent dyads (child variables; level 2) (see Table 3). In the second step, the level 1 variable (parent sex) was added to the model, and in the third step the level 2 variables (child sex and age) were added to the model, for each dependent variable (nonverbal behaviours). Finally, a second series of analyses were conducted to explore the interaction between parent and child sex by adding the interaction term (parent sex $\mathrm{x}$ child sex) to the model as the single level 1 variable in the first step. In the second step child age was controlled for by adding it to the model as a level 2 variable.

The findings of the intercept model suggested that a multilevel analytic approach was not statistically required for all of the nonverbal behaviours (i.e., parents within a dyad were not less independent than parents between dyads), possibly due to the low variability of some behaviours. Despite this, a multilevel approach was used to analyze all of the nonverbal behaviours in order to maintain consistency in analysis across variables, and since it is the most theoretically appropriate approach given the non-independence of the parent dyads ${ }^{29}$.

\section{Results}

\section{Descriptive Findings}


The nonverbal behaviours both mothers and fathers engaged in the highest proportion of the time were fidgeting (mothers: $M=0.24, S D=0.25$; fathers: $M=0.33, S D=0.33$ ), procedure related attending behaviours (mothers: $M=0.16, S D=0.16$; fathers: $M=0.16, S D=0.14$ ) and physical proximity (mothers: $M=0.19, S D=0.33$; fathers: $M=0.11, S D=0.29$ ) (see Table 2 for descriptive data).

\section{Relationship between Parent Nonverbal Behaviour and Child Pain Outcomes}

With regards to maternal nonverbal behaviour, a significant positive correlation was discovered between maternal physical comfort and reassurance and child pain intensity (FPS-R ratings), $r=.58, p=.00$, and a significant negative correlation was discovered between maternal procedure related attending behaviours and child pain tolerance, $r=-.45, p=.004$. No additional significant correlations were discovered between maternal nonverbal behaviours and child pain outcomes. With regards to paternal nonverbal behaviour, no significant correlations were discovered between any of the nonverbal behaviour categories and child pain outcomes measured (see Table 4).

\section{Relationship Between Parent Verbal and Nonverbal Behaviour}

A significant negative correlation was discovered between non-attending talk and nonverbal procedure related attending behaviours for fathers, $r=-.48, p=.002$, and mothers, $r=$ $-.46, p=.003$. No other significant correlations were discovered for mothers or fathers (see Table 5).

\section{Effect of Child Sex and Parent Sex on Parental Nonverbal Behaviour}

The first series of analyses examined the impact of parent sex and child sex on parental nonverbal behaviour using the multilevel regression equation, $Y_{i j}=\beta_{00}+\beta_{01}($ child sex $)+$ $\beta_{02}($ child age $)+\beta_{10}($ parent sex $)+u_{0 j}+r_{i j}$. The results of this set of analyses revealed no 
significant impact of parent sex or child sex on any of the nonverbal behaviours investigated, although there was a trend for fathers engaging in more fidgeting than mothers $\left(\beta_{10}=-0.094\right.$, $t(38)=-1.90, p=.065)$. There was also a significant impact of child age for fidgeting, with parents tending to engage in more fidgeting with older children $\left(\beta_{02}=.07, t(36)=2.21, p<.05, r\right.$ $=.29$ ). Child age further showed a trend for procedure related attending behaviours, and a significant impact on physical proximity. Specifically, parents tend to engage in more procedure related attending behaviours $\left(\beta_{02}=-.03, t(36)=-2.00, p=.05\right)$ and physical proximity behaviours $\left(\beta_{02}=-.06, t(36)=-2.28, p<.05, r=.25\right)$ with younger children. However, the finding for physical proximity behaviour is likely not meaningful given the high number of iterations required $(10,000)$ to converge on a model for this behaviour.

The second series of analyses examined the interaction between parent sex and child sex, controlling for child age, for each of the nonverbal behaviours investigated using the multilevel regression equation, $Y_{i j}=\beta_{00}+\beta_{01}($ child age $)+\beta_{10}($ interaction $)+u_{0 j}+r_{i j}$. This series of analyses revealed only a significant interaction for fidgeting $\left(\beta_{10}=-.04, t(38)=-2.04, p<.05, r=.20\right)$, with mothers engaging in more fidgeting with their sons compared to their daughters, and fathers not showing a sex differentiation.

\section{Discussion}

The objectives of the current study were to describe and compare mothers' and fathers' nonverbal behaviour during child cold pressor pain, examine the relationship between these behaviours and child pain outcomes, and examine the relationship between parental verbal and nonverbal behaviours. The most common behaviours both mothers and fathers engaged in were fidgeting, procedure related attending behaviours, and physical proximity. 
It was hypothesized that fathers would engage in more cold pressor task oriented nonverbal behaviours when their daughters were in pain compared to their sons, whereas mothers would not differentiate. With regard to mothers, the hypothesis was generally supported; mothers did not behave significantly differently with their sons and daughters. Thus finding is consistent with XXXX and colleagues" ${ }^{9}$ finding when examining mothers' verbal behaviour. Although mothers engaged in more fidgeting with boys compared to girls, caution is needed when interpreting the effect given the small difference in mothers' mean proportion of fidgeting with their sons relative to their daughters.

Contrary to the hypothesis, fathers' nonverbal behaviour did not differ between their sons and daughters. This finding is consistent with $\mathrm{XXXX}$ and colleagues ${ }^{9}$ results when examining fathers' verbal behaviour. As suggested by XXXX and colleagues ${ }^{9}$, it is possible that the cold pressor task was not a representative enough pain experience to elicit gender stereotyped behaviour. Future research could examine whether mothers' and fathers' nonverbal behaviour differs in clinical contexts. In a clinical sample, Hechler and colleagues ${ }^{30}$ found differences in mothers' and fathers' reported responses to their sons' and daughters' chronic pain. Given the low mean proportion scores for many of the nonverbal behaviours, it is also possible that mothers and fathers did not engage in the behaviours enough to detect a meaningful difference.

Although mothers' and fathers' nonverbal behaviour did not differ during their child's pain, there was a trend for fathers to engage in more fidgeting than mothers. This may suggest fathers experience a greater amount of restlessness or discomfort when watching their child in pain, or feel uncertainty about how to respond. Future research is needed to explore this possibility. 
As hypothesized, higher levels of maternal comfort and reassurance was associated with higher child pain intensity, and higher levels of maternal attending behaviours was associated with lower child pain tolerance. This finding is consistent with research on parental verbal behaviour demonstrating that talk focused on the child's pain (e.g., reassurance, attending talk) is associated with higher child reported pain ${ }^{3,9}$. It is thought that reassurance may increase child pain through alerting the child that the situation is distressing, reinforcing the child's distress, and/or prompting the child to display signs of distress ${ }^{2}$.

Contrary to the hypothesis, no relationship was discovered between paternal nonverbal behaviour and child pain outcomes. Given that mothers and fathers engaged in these behaviours with similar frequency, one explanation for this finding could be that children interpret their mothers' behaviours as being more meaningful than their fathers'. There is some evidence suggesting mothers and fathers may differentially influence child outcomes in the pain context. For example, one study found a relationship between parent pain catastrophizing and their child's rating of chronic pain intensity solely for mothers, not fathers ${ }^{30}$.

Another explanation is that mothers may be more reactive to their child's pain than fathers. The coding system and analyses used in the present study did not distinguish whether parental behaviour was parent initiated, or occurred in response to child speech or behaviour. Peterson and colleagues ${ }^{12}$ suggested the relationship discovered in their study between parental touch and child pain and distress was likely a result of parents being either reactive or proactive toward a child displaying distress. Using sequential analysis, Martin, Chorney, Cohen, and Kain $^{31}$ found that when parents responded with verbal reassurance to their child's distress following surgery, the child was more likely to continue displaying distress. For children who experienced more pain, it could be that mothers more so than fathers responded to their child's 
pain displays by engaging in comforting and reassuring, or attending behaviours. There is evidence supporting the notion that mothers and fathers respond in unique ways to their child's pain behaviours $^{32,33}$.

The hypothesis that nonverbal non-attending behaviours would be associated with lower levels of pain intensity and affect, and higher pain tolerance was not supported. This is contrary to research on verbal behaviour, which has demonstrated an association between parental nonattending talk or distraction and lower child reported pain ${ }^{3,9}$. However, in the current study parents only engaged in non-attending behaviours a very low proportion of the time (see Table 2), possibly not frequently enough to impact their child's pain outcomes. Future research could experimentally manipulate parental nonverbal behaviour in order to clarify whether nonverbal distraction influences child pain similarly to verbal distraction.

Finally, the hypothesis that parental nonverbal behaviours focused on the child's pain experience would be positively correlated to verbal attending talk, and negatively correlated to verbal non-attending talk, while the reverse would be true for nonverbal behaviours not focused on the pain experience, was partially supported. Higher use of parental non-attending talk (e.g., nonsymptom-focused talk, humor) was associated with lower levels of nonverbal attending behaviours (e.g., examining CPT equipment, modeling coping behaviours). This suggests that mothers and fathers who engaged in more verbal distraction, also did not draw attention to the task through their nonverbal behaviour. However, not all nonverbal behaviours were related to corresponding verbal behaviours, suggesting there is not necessarily a direct relationship between what parents say and do when their child is in pain.

The findings of this study have important clinical implications. Concurrent with recommendations regarding verbal behaviour during acute pain situations, the results suggest 
that, at least for mothers, parents should be encouraged to avoid engaging in nonverbal attending and reassuring behaviours when their child is in pain. Research should continue to examine the relationship between paternal nonverbal behaviour and child pain outcomes in order to provide insight into how to best direct fathers to behave during child pain.

There are several limitations in the current study worth highlighting. Although the cold pressor task is a widely used experimental pain task, it could be that parents behaved differently towards their children in this experimental setting than they would have in a more naturalistic pain context. Further, parents' knowledge of being videotaped and observed may have influenced their behaviour, thus limiting the generalizability of the findings. Also, as noted by XXXX and colleagues ${ }^{9}$, the fathers who participated in this study may represent a specific group of fathers who are more engaged in their child's life. Thus, their behaviour may not be generalizable to all fathers. Finally, the current study included a relatively small sample size, although it was determined using GPower $3.1 .3^{34}$ that the sample size was sufficient to detect small to medium effects for the primary analysis with power at 0.80 and alpha at .05 .

An important area for future research will be to compare mothers' and fathers' nonverbal behaviour using sequential analysis in order to provide insight into differences between parent and child initiated behaviours, and how they may differentially impact child pain outcomes over time. Another interesting area for future research might be to compare mothers' and fathers' verbal and nonverbal behaviour, and examine how they interact to influence children's pain outcomes, or determine which is more salient for children. Future research examining parents' nonverbal behaviour during clinical pain (e.g., immunization pain, procedural pain) in both clinical and healthy samples is also warranted to clarify whether parents' behaviour, and it's influence on children's pain outcomes, differs across settings and populations. Further research 
in clinical settings is also needed to develop a strong evidence base so recommendations for parents can be developed.

In conclusion, very little research has examined the role of fathers in pediatric pain. This study showed that, similar to prior work examining verbal behavior, mothers' and fathers' nonverbal behaviour did not differ in an experimental pain context. However, it was only mothers' reassuring and attending behaviours that were related to child pain outcomes, not fathers'. 


\section{Acknowledgements}

The authors have no conflicts of interest to disclose.

The acknowledgements section of this manuscript has been removed for the purpose of blinded peer review. 


\section{References}

1. McMurtry CM, Chambers CT, McGrath PJ, Asp E. When “don’t worry” communicates fear: Children's perceptions of parental reassurance and distraction during a painful medical procedure. Pain. 2010;150(1):52-58. doi:10.1016/j.pain.2010.02.021.

2. McMurtry, C.M., McGrath, P.J., Chambers. CT. Reassurance Can Hurt: Parental Behavior and Painful Medical Procedures. J Pediatr. 2006;148(4):560-561. doi:doi: 10.1016/j.jpeds.2005.10.040.

3. Walker LS, Williams SE, Smith CA, Garber J, Van Slyke DA, Lipani TA. Parent attention versus distraction: impact on symptom complaints by children with and without chronic functional abdominal pain. Pain. 2006;122(1-2):43-52. doi:10.1016/j.pain.2005.12.020.

4. Lewis C, Lamb ME. Father's influences on children's development: The evidence from two-parent families. Eur J Psychol Educ. 2003. doi:10.1007/BF03173485.

5. Moon EC, Chambers CT, Larochette A, Hayton K, Craig KD, Mcgrath PJ. Sex differences in parent and child pain ratings during an experimental child pain task. Pain Res Manag J Candadian Pain Soc. 2008;13(3):225-230.

6. Myers CD, Riley JL, Robinson ME. Psychosocial contributions to sex-correlated differences in pain. Clin J Pain. 2003;19(4):225-232. doi:10.1097/00002508-20030700000005 .

7. Zeman J, Shipman K. Children's expression of negative affect: Reasons and methods. Dev Psychol. 1996;32(5):842-849. doi:10.1037//0012-1649.32.5.842.

8. Lytton H, Romney DM. Parents' differential socialization of boys and girls: A metaanalysis. Psychol Bull. 1991;109(2):267-296. doi:10.1037//0033-2909.109.2.267. 
9. Note: The reference for the study on which the present study is an extension was removed for the purpose of blind review.

10. Walsh J, Eccleston C, Keogh E. Pain communication through body posture: The development and validation of a stimulus set. Pain. 2014;155:2282-2290. doi:10.1016/j.pain.2014.08.019.

11. Craig KD. The Social Communication Model of Pain. 2009;50(1):22-32. doi:10.1037/a0014772.

12. Peterson AM, Cline RJW, Foster TS, et al. Parents' Interpersonal Distance and Touch Behavior and Child Pain and Distress during Painful Pediatric Oncology Procedures. $J$ Nonverbal Behav. 2007;31(2):79-97. doi:10.1007/s10919-007-0023-9.

13. Keogh E. Gender differences in the nonverbal communication of pain: A new direction for sex, gender, and pain research? Pain. 2014;155:1927-1931. doi:10.1016/j.pain.2014.06.024.

14. Miller DC. Handbook of Research Design and Social Measurement: A Text and Reference Book for the Social and Behavioral Sciences. New York, NY: Longman; 1983.

15. Birnie KA, Petter M, Boerner KE, Noel M, Chambers CT. Contemporary use of the cold pressor task in pediatric pain research: a systematic review of methods. $J$ Pain. 2012;13(9):817-826. doi:10.1016/j.jpain.2012.06.005.

16. Von Baeyer CL, Piira T, Chambers CT, Trapanotto M, Zeltzer LK. Guidelines for the cold pressor task as an experimental pain stimulus for use with children. J Pain. 2005;6(4):218227. doi:10.1016/j.jpain.2005.01.349. 
17. Birnie KA, Noel M, Chambers CT, von Baeyer CL, Fernandez C V. The cold pressor task: is it an ethically acceptable pain research method in children? J Pediatr Psychol. 2011;36(10):1071-1081. doi:10.1093/jpepsy/jsq092.

18. Hicks CL, Baeyer CL Von, Spafford PA, Korlaar I Van, Goodenough B. The Faces Pain Scale - Revised : toward a common metric in pediatric pain measurement. Pain. 2001;93:173-183.

19. McGrath PA. Pain in Children: Nature, Assessment, and Treatment. New York, NY: Guilford Press; 1990.

20. McGrath PA, de Veber LL, Hearn MT. Multidimensional Pain Assessment in Children. Adv Pain Res Ther. 1985.

21. Bakeman R, Gottman JM. Observing Interaction: An Introduction to Sequential Analysis Second Edition. Cambridge: Cambridge University Press; 1997.

22. Chorney JM, Mcmurtry CM, Chambers CT, Bakeman R. Developing and Modifying Behavioral Coding Schemes in Pediatric Psychology : A Practical Guide. J Pediatr Psychol. 2015;40(1):154-164. doi:10.1093/jpepsy/jsu099.

23. Blount RL, Cohen LL, Frank NC, et al. The Child-Adult Medical Procedure Interaction Scale-Revised: an assessment of validity. J Pediatr Psychol. 1997;22(1):73-88. doi:10.1093/jpepsy/22.1.73.

24. Blount RL, Bunke V, Cohen LL, Forbes CJ. The Child - Adult Medical Procedure Interaction Scale-Short Form ( CAMPIS-SF ): Validation of a Rating Scale for Children' s and Adults’ Behaviors During Painful Medical Procedures. J Pain Symptom Manag. 2001;22(1):591-599. doi:10.1016/S0885-3924(01)00303-7. 
25. Blount RL, Devine KA, Cheng PS, Simons LE, Hayutin L. The impact of adult behaviors and vocalizations on infant distress during immunizations. J Pediatr Psychol. 2008;33(10):1163-1174. doi:10.1093/jpepsy/jsn030.

26. Cohen LL, Manimala R, Blount RL. Easier Said Than Done: What Parents Say They Do and What They Do During Children's Immunizations. Child Heal Care. 2000;29(2):7986. doi:10.1207/S15326888CHC2902_1.

27. Morris R, MacNeela P, Scott A, et al. Ambiguities and conflicting results: The limitations of the kappa statistic in establishing the interrater reliability of the Irish nursing minimum data set for mental health: A discussion paper. Int Nournal Nurs Stud. 2008;45(4):6456477. doi:10.1016/j.ijnurstu.2007.07.005.

28. Raudenbush S, Bryk A, Congdon R. HLM: Hierarchical Linear and Nonlinear Modeling. 2011.

29. Kenny DA, Kashy DA, Cook WL. Dyadic Data Analysis. New York: The Guilford Press; 2006.

30. Hechler T, Vervoort T, Hamann M, et al. Parental catastrophizing about their child's chronic pain: are mothers and fathers different? Eur J Pain. 2011;15(5):515.e1-e515.e9. doi:10.1016/j.ejpain.2010.09.015.

31. Martin SR, Chorney JM, Cohen LL, Kain ZN. Sequential analysis of mothers' and fathers' reassurance and children's postoperative distress. J Pediatr Psychol. 2013;38(10):11211129. doi:10.1093/jpepsy/jst061.

32. Goubert L, Vervoort T, De Ruddere L, Crombez G. The impact of parental gender, catastrophizing and situational threat upon parental behaviour to child pain: a vignette study. Eur J Pain. 2012;16(8):1176-1184. doi:10.1002/j.1532-2149.2012.00116.x. 
33. Vervoort T, Huguet A, Verhoeven K, Goubert L. Mothers' and fathers' responses to their child's pain moderate the relationship between the child's pain catastrophizing and disability. Pain. 2011;152(4):786-793. doi:10.1016/j.pain.2010.12.010.

34. Faul F, Erdfelder E, Lang A, Buchner A. G* Power 3 : A flexible statistical power analysis program for the social, behavioral, and biomedical sciences. Behav Res Methods. 2007;39(2):175-191. doi:10.3758/BF03193146. 


\section{A COMPARISON OF MATERNAL VS. PATERNAL NONVERBAL}

Table 1

Examples of each Behaviour Included in the Nonverbal Behaviour Coding System

\begin{tabular}{|c|c|}
\hline Nonverbal Behaviours & Examples \\
\hline Distraction & $\begin{array}{l}\text { Parental gesturing toward a non-task material } \\
\text { in the room }\end{array}$ \\
\hline Play & $\begin{array}{l}\text { A thumb war or hand game between parent and } \\
\text { child }\end{array}$ \\
\hline Humour & Parent makes a funny face or gesture \\
\hline $\begin{array}{l}\text { Non-procedure related encouraging/supportive } \\
\text { gestures }\end{array}$ & $\begin{array}{l}\text { Parent gives the child a "high-5" for a non-task } \\
\text { related accomplishment }\end{array}$ \\
\hline Physical comfort and reassurance & Parent holds child's hand or rubs their back \\
\hline Physical Proximity & $\begin{array}{l}\text { Parent moves closer to the child in an effort to } \\
\text { be comforting or reassuring }\end{array}$ \\
\hline Facial and behavioural sympathy & $\begin{array}{l}\text { Parent makes a sympathetic expression when } \\
\text { child makes a symptom complaint or places } \\
\text { their hand in the water }\end{array}$ \\
\hline Procedure related attending behaviours & $\begin{array}{l}\text { Parent touches or examines the cold pressor } \\
\text { task materials, or models coping behaviours }\end{array}$ \\
\hline $\begin{array}{l}\text { Procedure related encouraging/supportive } \\
\text { gestures }\end{array}$ & $\begin{array}{l}\text { Parent gives the child a thumbs up for keeping } \\
\text { their hand in the water }\end{array}$ \\
\hline Fidgeting & Parent taps their feet or bounces their knee \\
\hline Boredom & Parent slumps back in their chair \\
\hline Criticism & $\begin{array}{l}\text { Parent gives a disapproving facial expression } \\
\text { or physically intercepts their child from } \\
\text { engaging in a behaviour }\end{array}$ \\
\hline Other & Parent scratches their arm \\
\hline
\end{tabular}




\section{A COMPARISON OF MATERNAL VS. PATERNAL NONVERBAL}

Table 2

Mean Proportions (and Standard Deviations) of Parent Nonverbal Behaviour as a Function of Parent and Child Sex

\begin{tabular}{|c|c|c|c|c|c|c|}
\hline \multirow[b]{2}{*}{ Nonverbal Behaviours } & \multicolumn{3}{|c|}{ Mothers } & \multicolumn{3}{|c|}{ Fathers } \\
\hline & Combined & Boys & Girls & Combined & Boys & Girls \\
\hline \multirow[t]{2}{*}{ Distraction } & 0.07 & 0.06 & 0.08 & 0.03 & 0.03 & 0.03 \\
\hline & $(0.16)$ & $(0.09)$ & $(0.21)$ & $(0.07)$ & $(0.08)$ & $(0.05)$ \\
\hline \multirow[t]{2}{*}{ Play } & 0.01 & 0.01 & 0.02 & 0.06 & 0.08 & 0.04 \\
\hline & $(0.07)$ & $(0.02)$ & $(0.10)$ & $(0.19)$ & $(0.23)$ & $(0.15)$ \\
\hline \multirow[t]{2}{*}{ Humour } & 0.04 & 0.02 & 0.06 & 0.05 & 0.05 & 0.05 \\
\hline & $(0.07)$ & $(0.02)$ & $(0.09)$ & $(0.08)$ & $(0.08)$ & $(0.09)$ \\
\hline Non-procedure related & 0.00 & 0.00 & 0.00 & 0.00 & 0.00 & 0.00 \\
\hline encouraging/supportive gestures & $(0.00)$ & $(0.00)$ & $(0.00)$ & $(0.00)$ & $(0.00)$ & $(0.00)$ \\
\hline \multirow[t]{2}{*}{ Physical comfort and reassurance } & 0.05 & 0.03 & 0.08 & 0.05 & 0.05 & 0.05 \\
\hline & $(0.16)$ & $(0.07)$ & $(0.22)$ & $(0.16)$ & $(0.13)$ & $(0.20)$ \\
\hline \multirow[t]{2}{*}{ Physical Proximity } & 0.19 & 0.14 & 0.24 & 0.11 & 0.09 & 0.12 \\
\hline & $(0.33)$ & $(0.27)$ & $(0.38)$ & $(0.29)$ & $(0.28)$ & $(0.31)$ \\
\hline \multirow[t]{2}{*}{ Facial and behavioural sympathy } & 0.00 & 0.00 & 0.01 & 0.01 & 0.00 & 0.01 \\
\hline & $(0.01)$ & $(0.01)$ & $(0.01)$ & $(0.02)$ & $(0.01)$ & $(0.03)$ \\
\hline \multirow{2}{*}{$\begin{array}{l}\text { Procedure related attending } \\
\text { behaviours }\end{array}$} & 0.16 & 0.14 & 0.19 & 0.16 & 0.14 & 0.18 \\
\hline & $(0.16)$ & $(0.16)$ & $(0.16)$ & $(0.14)$ & $(0.15)$ & $(0.14)$ \\
\hline \multirow{2}{*}{$\begin{array}{l}\text { Procedure related } \\
\text { encouraging/supportive gestures }\end{array}$} & 0.00 & 0.00 & 0.00 & 0.00 & 0.01 & 0.00 \\
\hline & $(0.00)$ & $(0.00)$ & $(0.00)$ & $(0.01)$ & $(0.02)$ & $(0.00)$ \\
\hline \multirow[t]{2}{*}{ Fidgeting } & 0.24 & 0.27 & 0.20 & 0.33 & 0.34 & 0.32 \\
\hline & $(0.25)$ & $(0.28)$ & $(0.22)$ & $(0.33)$ & $(0.29)$ & $(0.37)$ \\
\hline \multirow[t]{2}{*}{ Boredom } & 0.00 & 0.01 & 0.00 & 0.03 & 0.04 & 0.02 \\
\hline & $(0.02)$ & $(0.03)$ & $(0.00)$ & $(0.12)$ & $(0.16)$ & $(0.05)$ \\
\hline \multirow[t]{2}{*}{ Criticism } & 0.01 & 0.01 & 0.01 & 0.00 & 0.00 & 0.01 \\
\hline & $(0.03)$ & $(0.02)$ & $(0.04)$ & $(0.01)$ & $(0.01)$ & $(0.01)$ \\
\hline \multirow[t]{2}{*}{ Other } & 0.06 & 0.08 & 0.05 & 0.05 & 0.04 & 0.05 \\
\hline & $(0.13)$ & $(0.16)$ & $(0.08)$ & $(0.07)$ & $(0.06)$ & $(0.08)$ \\
\hline
\end{tabular}




\section{A COMPARISON OF MATERNAL VS. PATERNAL NONVERBAL}

Table 3

The amount of variance in each dependent variable accounted for by level 1 and level 2 variables

\begin{tabular}{lcc}
\hline & \multicolumn{2}{c}{ Variance (\%) } \\
\cline { 2 - 3 } & $\begin{array}{c}\text { Level 1 } \\
\text { (Parent } \\
\text { Variables) }\end{array}$ & $\begin{array}{c}\text { Level 2 } \\
\text { (Child } \\
\text { Variables) }\end{array}$ \\
Nonverbal Behaviours & 99.93 & .07 \\
Distraction & 99.91 & .09 \\
Play & 99.82 & .18 \\
Humour & 100.00 & .00 \\
Non-procedure related & & \\
encouraging/supportive & & \\
gestures & 90.68 & 9.32 \\
Physical comfort and & & .07 \\
reassurance & 99.93 & .00 \\
Physical Proximity & 100.00 & 16.59 \\
Facial and behavioural & & \\
sympathy & 83.41 & .00 \\
Procedure related attending & & \\
behaviours & 100.00 & \\
Procedure related & & .29 \\
encouraging/supportive & & \\
gestures & & \\
Fidgeting & & \\
Boredom & & \\
Criticism & & \\
Other & 99.68 & \\
\hline
\end{tabular}




\section{A COMPARISON OF MATERNAL VS. PATERNAL NONVERBAL}

Table 4

Correlations Between Mothers' and Fathers' Nonverbal Behaviour and Child CPT Pain Outcomes

\begin{tabular}{|c|c|c|c|c|c|c|}
\hline \multirow[b]{3}{*}{ Nonverbal Behaviours } & \multicolumn{3}{|c|}{ Mothers } & \multicolumn{3}{|c|}{ Fathers } \\
\hline & CPT & Pain & Pain & CPT & Pain & Pain \\
\hline & Tolerance & Intensity & Affect & Tolerance & Intensity & Affect \\
\hline Distraction & .25 & -.21 & -.15 & .07 & .07 & -.28 \\
\hline Play & .12 & .04 & .02 & -.26 & .20 & .10 \\
\hline Humour & -.14 & .17 & -.08 & .04 & .08 & .13 \\
\hline $\begin{array}{l}\text { Non-procedure related } \\
\text { encouraging/supportive gestures }\end{array}$ & .09 & -.08 & .13 & - & - & - \\
\hline Physical comfort and reassurance & -.20 & $.58^{*}$ & .13 & .22 & .10 & .00 \\
\hline Physical Proximity & -.16 & .24 & .16 & .21 & .24 & -.28 \\
\hline Facial and behavioural sympathy & .21 & -.33 & -.24 & -.14 & -.04 & .07 \\
\hline $\begin{array}{l}\text { Procedure related attending } \\
\text { behaviours }\end{array}$ & $-.45^{*}$ & .09 & .24 & -.19 & -.00 & -.08 \\
\hline $\begin{array}{l}\text { Procedure related } \\
\text { encouraging/supportive gestures }\end{array}$ & .09 & .18 & .04 & .19 & -.06 & -.28 \\
\hline Fidgeting & .24 & -.23 & -.16 & .21 & -.14 & .22 \\
\hline Boredom & .09 & -.21 & .04 & -.14 & -.28 & .03 \\
\hline Criticism & -.14 & -.08 & -.17 & .20 & -.02 & -.16 \\
\hline Other & -.26 & .16 & .18 & .28 & .00 & .11 \\
\hline
\end{tabular}




\section{A COMPARISON OF MATERNAL VS. PATERNAL NONVERBAL}

Table 5

Correlations Between Mothers' and Fathers' Nonverbal Behaviour and Verbal Behaviour

\begin{tabular}{|c|c|c|c|c|}
\hline \multirow[b]{2}{*}{ Nonverbal Behaviours } & \multicolumn{2}{|c|}{ Mothers } & \multicolumn{2}{|c|}{ Fathers } \\
\hline & $\begin{array}{l}\text { Attending } \\
\text { Talk }\end{array}$ & $\begin{array}{c}\text { Non- } \\
\text { Attending } \\
\text { Talk }\end{array}$ & $\begin{array}{l}\text { Attending } \\
\text { Talk }\end{array}$ & $\begin{array}{c}\text { Non- } \\
\text { Attending } \\
\text { Talk }\end{array}$ \\
\hline Distraction & -.24 & .34 & -.21 & .15 \\
\hline Play & -.10 & .16 & -.27 & .35 \\
\hline Humour & .12 & .04 & -.02 & .08 \\
\hline $\begin{array}{l}\text { Non-procedure related } \\
\text { encouraging/supportive gestures }\end{array}$ & -.24 & .26 & $\ldots$ & - \\
\hline Physical comfort and reassurance & .15 & -.00 & -.03 & .09 \\
\hline Physical Proximity & .19 & -.01 & .02 & -.19 \\
\hline Facial and behavioural sympathy & .04 & -.05 & -.11 & .08 \\
\hline $\begin{array}{l}\text { Procedure related attending } \\
\text { behaviours }\end{array}$ & .23 & $-.46^{*}$ & .20 & $-.48 *$ \\
\hline $\begin{array}{l}\text { Procedure related } \\
\text { encouraging/supportive gestures }\end{array}$ & -.16 & .13 & .00 & .18 \\
\hline Fidgeting & .01 & .18 & .24 & -.04 \\
\hline Boredom & -.08 & -.07 & -.02 & -.21 \\
\hline Criticism & .18 & -.27 & -.15 & -.08 \\
\hline Other & .19 & -.17 & -.07 & .03 \\
\hline
\end{tabular}

Note. Fathers did not engage in any non-procedure related encouraging/supportive gestures, therefore a correlation was not possible.

$* p<.01$ 